\title{
Design with Perfect Sense: The Adoption of Smart Sensor Technologies in Architectural Practice
}

\author{
Maryam Abhari \\ San Diego State University \\ mabhari@sdsu.edu
}

\author{
Kaveh Abhari \\ San Diego State University \\ kabhari@sdsu.edu
}

\begin{abstract}
Recent development in the Internet of Things (IoT) has enabled real-time data-driven decision making in diverse industries. For example, over the last few years, the introduction of smart sensor technologies such as Watson IoT has led to various data-driven solutions in space planning, real-estate management, and energy conservation. Despite the recent development, these technologies are not widely used in architectural practice. In the wake of this trend, this research aims at understanding how architects and design professionals can be supported to further utilize smart sensor technologies in their practice. Based on the Technology-Organization-Environment framework and a series of interviews, the major influencing factors on user adoption were identified. This study contributes to both theory and practice by identifying six contributing factors, namely perceived risk and value, commitment to learn and collaborate, as well as knowledge and trust.
\end{abstract}

\section{Introduction}

Architectural analysis and design is a resource intensive, ever-changing, and time-consuming process. Improving the efficiency of architectural analysis and design is one of the most challenging goals of architecture firms. The need for delivering quality service to clients while reducing the time and costs and, at the same time, tackling the project staff shortage are primary issues in many architecture projects. However, new technologies such as sensors technology provide potentials for more efficient processes from data collection and analysis to design recommendations. The nature of these technologies forces architects to challenge prior design practices. While technological innovation has the potential to improve design, design process, and productivity, the literature shows that substantial technical and organizational barriers exist, which inhibit the effective adoption of these technologies [15, 17]. Recognizing these challenges is necessary to improve the design process, respond to the clients' needs, and eventually improve the users' well-being.

Increased use of smart sensor technologies (SST) is leading to the recognition of their influence on design outcomes (e.g. user experience) by architects. However, the majority of the architects fail to acknowledge the influence of SST on the design process and therefore, they hesitate to explore the potentials of these technologies. Although literature in other disciplines discussed the factors that influence the initial adoption of SST (e.g. healthcare, energy, urban planning), this issue has never been a matter of prime interest in the architecture context. Hence, the purpose of this paper is to shed lights on the challenges that architectural organizations face in adopting SST. In particular, we tried to answer: what are the factors affecting architecture firms and particularly principal architects' decisions on SST initial adoption and use?

In particular, this study investigates how architects' perception of these technologies affect their organizations' willingness to consider SST as a new design tool in their practice. Understanding these challenges is important not only for architectural design but also for economic growth and more importantly for the well-being of the users. In order to explore why architects may hesitate to utilize SST proactively in design process, we try to identify which technological, organizational and environmental factors influence the adoption of SST in architectural practices.

The rest of this paper is structured as follows. First, we present definitions of basic terms such as smart technology and smart sensors in architectural practice, and then discuss the theoretical background of technology adoption in the light of Tornatzky and Fleischer's technology-organization-environment (TOE) Framework [25]. The TOE framework explains how firms' decision makings to adopt technological innovations are affected by three different contexts, namely technology, environment, and organization [2, 
25]. Then, we describe our research methodology. Following the methodology, we report on the findings by describing the influencing factors including the challenges. Finally, we summarize the results in a framework, provide six recommendations, and present future research directions in the conclusion.

\section{Background}

The architecture industry is facing technological transformations, which introduces new challenges for architects and their organizations. Introduction of each new technology results in dramatic changes in the industry. For example, the industry is embracing new methods of information sharing and adopting new technical concepts such as building information modeling (BIM), smart materials, virtual reality (VR), internet of things (IoT), and related applications each of which is supporting the practice. However, it is essential for architects to view technology not only as a supportive tool but as an inspirational platform to generate efficient and desirable design solutions.

How BIM has been adopted by the industry exemplifies the typical process of a new technology adoption by architects. Many of the decisions that affect buildings performance and users' experience if not made early in the design process are difficult to change once the building's initial design phases are completed. In the conventional design approach, architects, engineers, and contractors operate largely independently of one another without utilizing an integrated approach to design and construction. With the rise in need of more efficient and reliable construction processes, this conventional approach was not a solution anymore. The design and construction process remained poorly coordinated until BIM technology arrived. BIM with a set of technologies and processes facilitate the coordination of AEC (architecture, engineering, and construction) professionals from the earliest phases of design. Even though, the concept of this technology formed in the 1970s [11], it took years for architects and engineers to adopt BIM in practice. Cost, training, lack of client's interest, team-dependency and coordination difficulties are among the top reasons for slow adoption of BIM. Despite all these challenges, today, BIM is having a profound impact on the industry.

Chaos Group conducted a study in 2017, showing how some of the recent trends such as BIM adoption and VR are transforming the industry. The survey was conducted among 5,769 architects and architectural professionals from over 70 countries. According to this study, $70 \%$ of participants noted that the increased dependence on technology is the major change in the industry over the past three years. However, tight deadlines and limited budgets are the top concerns in utilizing those technologies [3]. The importance of training for an effective implementation of new technologies has been also emphasized [18].

\subsection{Architecture Design and IoT}

Besides BIM and VR, the IoT is another fastgrowing technology with numerous applications in architecture. Many businesses in construction, facility management, and real-estate are embracing IoT technologies to minimize the operational cost of built environments and improve their users' well-being. Learning thermostats, energy tracking switches, connected motion sensors, smart cameras, and smart lights and shades are all increasingly found in buildings. These connected devices use embedded sensors and the Internet to collect and communicate data with each other and their users, seamlessly integrating the physical and digital worlds inside the buildings [e.g. 13, 21, 22, 24, 36]. Recent studies show that smart devices were added to the buildings after they are built mainly to improve buildings performances, energy and water efficiency, buildings security, and occupants' well-being [18]. Despite this trend, architects and interior designers rarely use IoT technologies proactively in the design process. For example, SST can collect data about spaces and occupants to assist architects and designers in optimal design solution development for similar projects in the future.

\subsection{Smart sensor technology in architecture}

The definition of smart technology in architecture is not well-established yet. Studies on this subject show that theories of adopting smart technologies in architecture are also very limited. Encyclopedia of Information Science and Technology defines smart technology as technologies that are capable of learning, anticipating, thinking and reasoning [19]. Accordingly, we define SST as the technologies that can sense environmental signals such as movement, temperature, light, and noise, then communicate, analyze data, and draw conclusions to adapt automatically, modify or trigger behavior.

SST is evolving as the next generation of the IoT technology that autonomously or semi-autonomously collects and process environmental data. Any object with sensors can be a connected node in the IoT network or within any number of autonomous systems such as smart buildings and cities. This technological advancement can be a practical solution to facilitate and improve design processes for architects to help generating data-driven and evidence-based design.

SST has been targeted in prior research for more than 40 years [8]. The existing research mainly 
focused on opportunities and challenges [2, 8]. However, research about the actual involvement of SST as an integrated part of the design process in the architectural practice is limited. Even though there exists some research about the application of smart technologies in the architectural industry, the reason behind the slow adoption of these technologies has not been covered yet.

In this study, smart sensors are referred to devices that take input from the physical environment and response upon detection of specific inputs. They are used as monitoring and control mechanisms in a wide variety of environments. Smart sensors enable more accurate and automated collection of environmental data over open or closed network. Data transmitted from physical environments work as a valuable source of information for architects and design professionals to facilitate design processes and to solve functional design problems such as space planning and layout, space utilization, occupants' circulation, ventilation, energy and water efficiency, buildings safety and security, and accessibility.

Researchers have studied the challenges of the IoT $[5,23]$ but very few consider the opinions and behaviors of the architects and design professionals who are the key players in this process. Hence, our goal in this study was to investigate the challenges that principal architects are facing to adopt SST in their design process. The integration of smart technologies and architecture not only enhance users' well-being but also reinvents the way they interact with the physical spaces.

Research shows that tight project deadlines and budget restrictions are preventive factors for adopting a new technology in architectural practices [3]. Collaboration, coordination, and communication were also cited as the factors hindering the adoption of new technology or innovation in architectural practice [6, 12]. Previous studies also explained that these constraints are more impeding for small and mediumsized organizations who have technical resources as opposed to larger organizations [28].

\subsection{Example of SST}

Watson IoT for buildings captures data from sensors and uses Watson artificial intelligence (AI) to provide recommendations that can be operationalized by Tririga software. Tririga is an integrated space management system that can increase the operational, financial and environmental performance of the spaces (e.g. facilities and real estate). Tririga combines, analyzes, and visualizes data from sensors and equipment for facility, space, and energy management. Tririga with a sensor network can be used for analyzing space utilization and accelerating space configuration, as well as reducing energy consumption to meet long-term sustainability goals [14]. As an example of this technology application, we can refer to the collaboration of IBM with Siemens in 2016 to develop a new technology for Siemens' Navigator platform and a joint real estate offering [33]. Verdantix analysis of this partnership shows the successful integration of energy management into facility optimization strategies, which led to a more efficient management of diverse and difficult-to-service building portfolios [33].

Increased use of SST such as IBM Tririga is leading to recognition of their influence on design outcomes - for example, user experience and building performance by architects. The value proposition of these technologies has been demonstrated empirically. Likewise, a growing number of companies or building owners are starting to adopt these technologies to improve building's efficiency, lower operational cost and more importantly to enhance user's wellbeing. The reality is that demand for smart building technologies will continue to grow. While architects acknowledge the influence of incorporating this technology on building management, they are cautious in proactively use the technology in the early phase of design. Lack of collaboration between building industry stakeholders also slows down this adoption, which consequently prevents clients from achieving the desired outcomes [34].

We believe architects can use SST technologies in three ways. First, architects can employ these technologies to collect data from existing buildings to inform the design of new buildings. Data collected from existing airports, hospitals, concert halls, and stadiums provide ample evidence on space usage, traffic, circulation and user experience guiding similar projects in the future. Second, architects can collect data from the environments that need to be renovated, remodeled, or rebuild. The collected data has a potential to reveal the positive and negative aspects of the existing design and therefore direct the future design. Third, SST empowers architects to experiment with new ideas in the planning or programming phases. For example, SST enable architects to experiment with new materials and collect objective data from potential users even before the design phase.

\section{Technology Adoption}

While innovation in architectural practice supports a more efficient design process, it exposes architects to the risk of failure because the new developments eliminate or change the organizational practices that have been well-established for several years [9]. At the individual level, rethinking the design processes is also challenging due to the new 
requirements that determined by systems such as Tririga. Architects and design professionals, unfortunately, tend to use new technologies without changing their traditional design approach especially in the way they define design problem in the first place. Therefore, they prefer to discard the new technology application and its befits altogether. As Christopher Alexander, an influential architect and design theorist, put it "when a designer does not understand a problem clearly enough to find the order it really calls for, he falls back on some arbitrary chosen formal order [1]."

To understand the relationship between SST as a new technology and the design process at organizational level, we used the TechnologyOrganization-Environment Framework (TOE). This framework helps outline the theoretical background of technology adoption. The TOE framework explains how firms' decision makings to adopt technological innovations are affected by three different elements, namely technological context, the organizational context, and the environmental context $[25,32]$. From TOE perspective, technological context refers to both the internal and external technologies relevant to the firm; organizational context associated with organizational resources and boundaries such as scope, size, and structure; and environmental context is the external arena in which a firm conducts its business [32].

We used the TOE framework since it was frequently used in the literature to describe the processes of technological innovation adoption and implementation [16, 20]. In Information Systems research, many studies also applied this framework to identify the factors affecting the adoption process from an organizational or managerial perspective [31]. Moreover, this framework provides a systematic and relatively holistic approach and thus offers a common ground to compare the study outcomes with existing research and guide the future investigation [2]. The TOE framework also emphasizes perceptual factors along with contextual drivers which are the key to innovation adoption research [10]. Furthermore, the TOE framework is an organization-level theory and therefore, it suited our research better than other theories such as Technology Acceptance Models [26]. Therefore, we used this framework to design our empirical study and interpret the findings.

\section{Methodology}

We conducted exploratory interviews with domain professionals to identify relevant factors influencing the slow adoption of SST as an integrated factor in design processes. In this section, we describe our methodology in three parts: selecting interviewees, conducting interviews, and analyzing transcripts and interview notes.

First, we selected architects and design professionals who have either experience with SST or had attended at least three seminars/workshops related to the application of these technologies in the past 15 months. We interviewed 17 professionals during an event organized by the American Institute of Architects (AIA). To increase our sample size, we contacted more professionals who meet our criteria using the AIA member directory. In total, we informally interviewed 29 architects and design professionals (see, Table 1, for the interviewees' profile). To allow in-depth analysis of our interviews, we asked all professionals whether we could record the interviews to transcribe them afterward. In total, 25 out of 29 interviewees were recorded and transcribed with an average of 25 minutes per interview. Only four experts denied the recording where we collected data through intensive note-taking.

We conducted our semi-structured interviews either in person or via phone to focus on our aim to identify influencing factors and related organizational challenges based on three themes of technology, organization, and business environment [4, 26, 27]. For the technological context, we considered (a) perceived direct benefits (e.g. improvements made by SST to the internal design process), (b) perceived indirect benefits (e.g. improvements made by SST to the design implementation), and (c) cross-technology compatibility (e.g. SST integration with other existing technologies within and beyond firm boundaries). For organizational context, we focused on (a) financial readiness (e.g. resources available for adopting the SST), (b) technological readiness (e.g. the level of new technology usage and management in a firm), and (c) top management support (e.g. the alignment between business goals, business support and SST potential benefits). Finally, for the environmental context, we looked at (a) perceived pressure from the industry (e.g. the technological capability of the firm's competitors), (b) perceived pressure by partners (e.g. the contractors' willingness to use data-driven design approach), and (c) perceived pressure from clients (e.g. customers' demand and expectation).

After verifying the interviewees' familiarity with SST, we first asked them about the factors affecting SST adoption in the design phase (e.g. what are the benefits or opportunities associated with the use of SST? what are the risks or barriers associated with the use of SST?). Our follow-up questions were more specifically focused on the nine above-mentioned technological, organizational and environmental factors suggested by the literature [4, 20, 26, 27]. We also asked the interviewees: who are involved in the 
decision of adopting SST? What process would your firm go through prior to the decision to use SST?

Table 1. Interviewees' profile

\begin{tabular}{lll}
\hline \multirow{2}{*}{ GENDER } & 21 & males \\
& 8 & females \\
\hline \multirow{3}{*}{ AGE } & 10 & from 20 to 35 \\
& 14 & from 36 to 55 \\
& 5 & above 55 \\
\hline BUSINESS & 18 & small $(<9$ employees) \\
SIZE & 8 & medium (10 and 49) \\
& 3 & larges ( $>50$ employees $)$ \\
\hline \multirow{2}{*}{ YEARS OF } & 6 & less than 5 years \\
EXPERIENCE & 13 & between 5 and 20 years \\
& 8 & above 20 years \\
\hline & 16 & project architects \\
JOB ROLE & 4 & principals \\
& 6 & designers \\
& 3 & other design professionals \\
\hline
\end{tabular}

The interviews provided insights on (a) how architects define SST and its applications in architectural practices, (b) why architectural firms choose to adopt or not to adopt SST in design processes, (c) what factors contribute to their personal perception of SST adoption, and (d) how they adjust their adoption based on the perception of value and risk and prior experience.

Upon the completion of interviews, we analyzed our data using the structured content analysis approach by coding relevant statements of the transcribed interviews using open and selective coding. The following steps were taken to analyze the interview data $[29,35]$. To minimize coding errors and subjective influences, two persons were involved in the coding process. This resulted in 212 relevant statements which we grouped into similar challenges. Based on this, we derived influencing factors, compared properties for a common language and classified them according to the dimension of the TOE framework at three levels of technological, organizational, and environmental opportunities or barriers. Then, we applied hierarchies to the properties by identifying the key categories and their subcategories. At this phase, we cross-validated and verified the emerged categories and sub-categories by using the literature. Finally, we labeled each category based on the empirical instances. We also contacted five follow-up interviewees to validate the final labels.

\section{Findings}

As a result of our empirical study, we were able to identify major influencing factors which correspond to the low adoption of SST in the architectural practice in three contexts of organization, technology, and environment (see, Tables 2, 3 and 4).

After applying hierarchies to the highly-cited factors, we identified the following six key categories and the associated sub-categories that drive the intention to incorporate SST in the design process (perceived risk, perceived value, commitment to learning, commitment to collaborate, prior knowledge and trust). We also identified the possible relationships between the key categories. The results are summarized in Figure 1.

These categories are aligned with the governing principles of architecture firms, namely innovation, practice, and negotiation. While the study confirmed the previous studies' findings in other contexts $[4,16$, $20,26,27]$, it offers new insights into new technology adoption by architectural firms. In the following, we describe each category and discuss their role based on the results of our interviews.

Table 2. Example of organizational barriers

\begin{tabular}{ll}
\hline ORGANIZATIONAL BARRIERS \\
\hline - & Organizational readiness \\
- & Lack of emporization attitude to innovation \\
- & Loor knowledge mant and support \\
- & Inadequate personnel to implement digital \\
& innovation \\
- & Lack of collaboration \\
- & Insufficient team commitment \\
- & Insufficient management budget \\
- The unwillingness of the firm to invest \\
- Lack of budget for team training \\
- Hack of R\&D budget \\
\hline
\end{tabular}

Table 3. Example of environmental barriers

\begin{tabular}{cl}
\hline & ENVIRONMENTAL (EXTERNAL) \\
BARRIERS \\
\hline - & Fear of increase in labor cost \\
- & Inadequate level of details needed \\
- & High standard \\
- & Fearadequate design fee \\
- & Fear of technology changes \\
- & Fear of coordination failure \\
- & Lack of ex client's need change \\
\hline
\end{tabular}




\section{Table 4. Example of technological barriers}

\begin{tabular}{ll}
\hline TECHNOLOGICAL BARRIERS \\
\hline - & Performance of SST \\
- & The mobility of SST to handle complex \\
- & Limsues \\
- & Lack of trust in SST \\
- The high cost of digital tools \\
- The high cost of setting up equipment \\
- (sensors) \\
- Lack of equipment \\
- Insufficient knowledge \\
- Lack of training \\
- Lack of technical demonstration \\
- Inadequate R\&D knowledge \\
- Unavailability of new digital tools \\
- The high cost of equipment maintenance
\end{tabular}

Table 5. Categories and sub-categories

\begin{tabular}{|c|c|}
\hline CATEGORY & SUB-CATEGORY \\
\hline Perceived risk & $\begin{array}{l}\text { - Design creativity } \\
\text { - Design complexity } \\
\text { - Design time } \\
\text { - Design cost }\end{array}$ \\
\hline Perceived value & $\begin{array}{l}\text { - Evidence-based design } \\
\text { - Design Process } \\
\text { - Professional portfolio }\end{array}$ \\
\hline $\begin{array}{l}\text { Commitment to } \\
\text { learn }\end{array}$ & - Learn to use SST \\
\hline $\begin{array}{l}\text { Commitment to } \\
\text { collaborate }\end{array}$ & $\begin{array}{l}\text { - Collaborate with non- } \\
\text { traditional consultants }\end{array}$ \\
\hline Antecedents & $\begin{array}{l}\text { - Trust in SST } \\
\text { - Knowledge of SST }\end{array}$ \\
\hline
\end{tabular}

\subsection{Perceived risk}

The notion of control is an important risk factor for architects. They feel they may lose control over several design factors such as design creativity, design complexity, design time, and design cost.

Design creativity. Interviewees believed that utilizing SST in design processes generates additional constraints for creative design. Designers tend to identify design problems and formulate unique design solutions with an open mind. Data-driven design approach affects their design thinking process as they are not able to freely think about different design solutions, or design solutions that may not meet the recommendations generated by SST. On the other hand, designers already deal with several constraints such as zoning, building codes and regulations, accessibility, sustainability, and other standards which affect their flexibility in choosing their preferable design solutions. Therefore, they are not willing to generate additional constraints in their design by their own choice.

Design complexity. Interviewees argued that while SST might help with simple and straightforward projects, the technology as yet lacks the ability to handle complex problems or assist with decisionmaking when unforeseen issues occur. Moreover, a few participants believed while the existing tools have been programmed for standard projects, the tools add unnecessary complexity to the simple projects.

Design time. Time management is an issue for all architectural projects. Architecture firms need more time to educate project teams and to coordinate with additional consultants such as sensor technologists from the early phases of the design. Therefore, many interviewees were not interested in taking the risk of new technology while they are under pressure from their clients for on-time project delivery.

Design cost. Architecture projects are not only time sensitive but also cost sensitive. Some of the participating professionals believed that using SST would add considerable cost to their practice without immediate values. They argued for this additional cost, charging higher fee is not foreseeable in many cases even when the client is interested in the technology or data-driven design. Some factors influencing organizations' expenses include the cost of digital tools and setting up equipment such as sensors, the budget for team training, cost of equipment maintenance, $R \& D$ budget, and labor cost. To cover these additional expenses, firms should increase their service fees which affect their firm competitiveness and client retention rate.

\subsection{Perceived value}

While the participants believed that the lack of control on the design process would negatively affect their ability to innovate along with other risks mentioned earlier, they acknowledged some values associated with SST. Their perceived value is associated with evidence-based design, design process, and design portfolio.

Evidence-based design. Interviewees believed that offering a data-driven design empowers them to solve the functional problems with the support of factual evidence and therefore, effectively negotiate the design with their client. In contrast with the literature, the participants did not believe that utilizing SST could lead to a better user experience. However, they believed that supporting their design with data 
would help them to express their ideas and to negotiate the decisions with their clients, and consultants.

Design process. While the participants believed that the lack of control on the design process would negatively affect their creativity especially during the conceptual and schematic design phase, they argued that using SST would facilitate pre-design processes such as site and building analysis. They believed that data available from similar projects would help them to accelerate the initial design phases. It would be also valuable to use the data collected from similar projects to solve design problems with no obvious solutions.
Professional Portfolio. Some participants argued that utilizing SST would add credentials to their professional practice and enhance their reputation. They noted, this reputation might attract more clients and maintain their brand image as a forward-looking practice. Knowing that their practice is keeping up with technology attracts more clients looking for such services. However, not all the clients would be willing to pay a higher fee for the application of SST in design unless architects could guarantee the return on investment, which is not always possible except in case energy conservation.

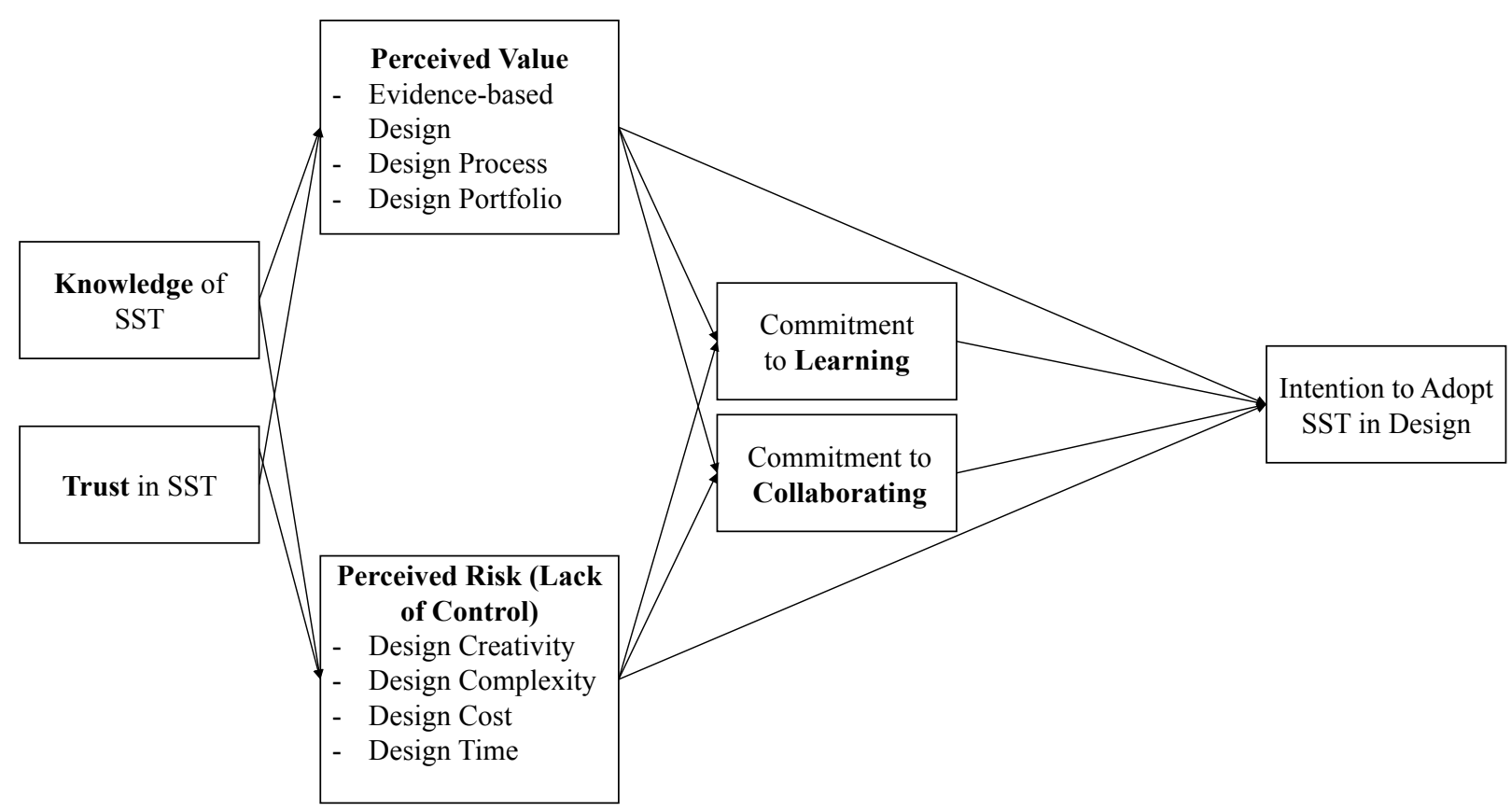

Figure 1. Theoretical framework explaining SST adoption by architectural firms

\subsection{Commitment to learning}

Incorporating SST indeed associates with upfront educational investments for professionals and their clients. Lack of sufficiently trained personnel is a significant constraint hindering the use and adoption of the technology in the industry. Majority of participants believed that commitment to learning is a significant factor in adopting a new technology among architectural firms. They find it difficult to take a leading role to initiate this transformation and provide the necessary education for their design team. They also argued that communicating the value of SST and educating current and potential clients increase the project's professional fees. Necessary education and training are compromised by tight budget on the most of projects. Therefore, maximizing values and minimizing risks are not instrumental unless there is a commitment to learning by the team and commitment to training by the top management team.

\subsection{Commitment to collaborating}

It is not a common practice in conventional design approach to bring an IoT or sensor network technologist as a core team member who is involved from the earliest design phases. However, to minimize the risks and maximize the benefits of new technologies, design professionals may find greater benefit in partnering with IoT technologists to take a more active role in the design process. In a truly collaborative relationship, the designer and technologist can advance the likelihood that SST will facilitate the design process while improving users' 
experience. Majority of the participants often find it frustrating to coordinate with several engineers and non-traditional consultants from the early phase of the design, especially when they have no working experience with them in the past.

\subsection{Role of Knowledge and Trust in SST}

We identified two factors defining the architects' perception of SST values and risks: their knowledge of and their trust in SST. Lack of trust is related to the technical capability to support creative work and address the requirements (e.g. building code). Lack of knowledge refers to the insufficient knowledge of team members, lack of training in technology, and lack of organizational interest and willingness in the knowledge acquisition in general. Among the knowledge factors, the organizational knowledge into the new technologies (concept and applications) -not necessarily SST- was the most prominent factor mentioned by the majority of participants.

\section{Recommendations}

The study provides six recommendations for SST adoption in architectural practice. First, firms need to start with principal architects and project managers who have the experience to work with nontraditional technologies. Architecture firms should recognize that the applications of SST include both conventional design process and new technological approach and this blend requires a new form of training and commitment to change (e.g. balance between intuitive and data-driven design). While this combination is not an entirely new process for some architectural firms, it requires to be led by principal architects or project managers who can accept this dual responsibility and effectively incorporates both traditional and new methods. Further, this process requires project managers to effectively collaborate with a new team of consultants. As shown in this study, SST adoption requires a commitment to collaboration with non-traditional consultants like IoT specialists and sensor network engineers who are not necessarily familiar with the architectural practice. Principal architects and project managers should be able to invest time in training and coordinating with these consultants before proposing or initiating any SST-enabled project.

Second, architectural firms should recognize the need to conduct SST cost-benefit analysis at the preplanning phase. If the architects allocate upfront time, prior to any use of SST, they can address challenges more effectively, especially those associated with project cost, time and complexity. For example, SST adoption often requires significant financial investments or co-investment with the client. Because of the novel nature of SST, return on these investments is not guaranteed. To receive investment, a rigorous cost-benefit analysis is necessary to convince decision-makers that these investments will pay off. Likewise, SST is not instrumental to so many projects and it may add unnecessary cost and complexity. Therefore, it should be only used when the conventional methods have already failed to provide an optimum solution. Allowing time for pre-planning not only help architects detect foreseeable challenges but also allow them to properly plan for handling the challenges identified in this study.

Third, principal architects and project managers need to work with teams that have enough knowledge on data-driven design process to explore potential avenues for SST adoption. The success of a datadriven design also depends on a clearly defined and well-executed design process that needs a shared language and consolidation and calibration of heterogeneous and sometimes potentially contradictory perspectives among the team members. By dividing up human resources into smaller, more focused teams with diverse knowledge of new technologies, resources can be more effectively directed toward developing appropriate and successful SST adoption. This approach may also increase the control of principal architects or project managers leading the project and minimize the unnecessary complexity

Fourth, principal architects with the help of consultants need to choose the SST package that is best for the project (i.e. different sensor combinations and data collection and communication protocols). The type of technology may have potential ramifications because they may change the direction of the project. Different SST (software and hardware) require different expertise, interface technologies, and development techniques and provide different types of data. As such, they can potentially affect not only future phases of the project but also phases already completed. Furthermore, while SST could be an effective or efficient solution to the problem at hand (e.g. energy efficiency), it could potentially be nonviable or bring a little value to the whole project. When deciding which SST solution to adopt, it is important to assess whether it brings an optimum design solution for just a portion of the project or the entire project as the client expected.

Fifth, principal architects need to establish trust in SST within the project team and top management. One approach to establishing trust is to point to the best practices. By validating that an SST application has been effective in other project settings, the principal architects can provide evidence that the introduction of SST would make economic sense. By 
establishing trust, the architect can gain both management and client support to accelerate the design process, particularly by securing the required resources.

Lastly, principal architects and project managers should be flexible when adopting and implementing SST and understand the trade-off between evidencebased design and traditional design. To effectively integrate SST with architectural practice, flexibility in terms of design options, project plan, design process and design outcome is necessary throughout the duration of the project. Like working with any new technology, this flexibility helps architects to be open to new opportunities for addressing clients' needs and expectations.

\section{Conclusion}

Technological innovation has constantly opened challenges and opportunities for the architects. For example, fast-growing technologies such as the widespread adoption of BIM, VR, AI, IoT, and related technologies are having a profound impact on the architectural design processes. Despite the existence of smart technologies for some time, their prevalence is not widespread in architectural practice, and thus their potential largely untapped. Investigating this gap, in this paper, we examined the low adoption of SST in architectural design. As a result of our empirical interviews with 29 professionals, we identified four influencing factors and two antecedents related to the technological, organizational and environmental contexts of architectural practice.

The presented model which is based on the TOE framework can contribute to both, research and practice. Our findings can be used for future empirical research on SST adoption. This framework offers insights into both benefits and risks while introducing two new mediating constructs namely commitment to learning and commitment to collaborating. Our findings also contribute to the technology adoption literature by identifying the barriers faced by professionals in this field. From the practical standpoint, our study can be used as a starting point to not only educate architects on SST applications but also to develop the next generation of SST to better support efficient design solutions for architecture projects.

In recommending this framework, we should also note its limitations. While the framework was developed to be as generalizable as possible, it was developed based on a series of interviews with a few professionals. Therefore, additional checks for validity and reliability would be prudent. The study also calls for more scholarly attention to the role that perceived value and risk play in influencing technology adoption behavior. We suggest that researchers employ the proposed framework to develop new rigorous quantitative studies to further validate and clarify the findings. For example, further investigation is needed in other to examine the generalizability of the model as well as its impacts on architectural practice and outcomes.

\section{References}

[1] Alexander, C., Notes on the Synthesis of Form, Harvard University Press, 1964.

[2] Baker, J., The Technology-OrganizationEnvironment Framework, Springer, New York, 2012.

[3] Chaos Group, 2017 Architectural Visualization Technology Report, 2017.

[4] Chau, P.Y.K., and K.Y. Tam, "Factors Affecting the Adoption of Open Systems: An Exploratory Study", MIS Quarterly 21(1), 1997, pp. 1-24.

[5] Chen, Y.-K., "Challenges and opportunities of internet of things", 17th Asia and South Pacific Design Automation Conference, 2012, pp. 383-388.

[6] Chiu, M.L., "An organizational view of design communication in design collaboration", Design Studies 23(2), 2002, pp. 187-210.

[7] Chong, C., S.P. Kumar, and S. Member, "Sensor Networks: Evolution , Opportunities , and Challenges", 91(8), 2003.

[8] Corsi, C., "Smart Sensors: Why and when the origin was and why and where the future will be", Proceedings of SPIE - The International Society for Optical Engineering, International Society for Optics and Photonics (2013), 899302-899312.

[9] Davila, T., M. Epstein, and R. Shelton, Making Innovation Work: How to Manage It, Measure It, and Profit from It, Updated Edition, Pearson Education, 2012.

[10] Downs, G.W., and L.B. Mohr, "Conceptual Issues in the Study of Innovation", Administrative Science Quarterly 21(4), 1976, pp. 700.

[11] Eastman M, C., D. Fisher, G. Lafue, J. Lividini, D. Stoker, and C. Yessios, "An Outline of the Building Description System", Carnegie-Mellon University Research $R, 1974$, pp. 1-23.

[12] Guy, S., and G. Farmer, "Reinterpreting sustainable architecture: The place of technology", Journal of Architectural Education 54, 2001, 140-148.

[13] Hui, T.K.L., R.S. Sherratt, and D.D. Sánchez, "Major requirements for building Smart Homes in Smart Cities based on Internet of Things technologies", Future Generation Computer Systems 76(1), 2017, pp. 358-369. 
[14] IBM, "IBM Tririga", Tririga Resources. https://www.ibm.com/us-en/marketplace/ibmtririga/resources

[15] Intrachooto, S., "Technological innovation in architecture: effective practices for energy efficient implementation", 2005.

[16] Jia, Q., Y. Guo, and S.J. Barnes, "E2.0 postadoption: Extending the IS continuance model based on the technology-organization-environment framework", Proceedings of the International Conference on Electronic Business (ICEB), Pergamon (2016), 695-707.

[17] Johnson, R.E., and E.S. Laepple, "Digital Innovation and Organizational Change in Design Practice", 2003.

[18] Khaddaj, M., and I. Srour, "Using BIM to Retrofit Existing Buildings", Procedia Engineering, (2016), 15261533.

[19] Khosrow-Pour, M., ed., Encyclopedia of Information Science and Technology, Third Edition, IGI Global, 2015.

[20] Leung, D., A. Lo, L.H.N. Fong, and R. Law, "Applying the technology-organization-environment framework to explore ICT initial and continued adoption: An exploratory study of an independent hotel in Hong Kong", Tourism Recreation Research 40(3), 2015, pp. 391-406.

[21] McIntyre, L., "Smart technologies in buildings: exploring the conflicts and opportunities for health and wellbeing", Design4Health Conference, (2018).

[22] Minoli, D., K. Sohraby, and B. Occhiogrosso, "IoT Considerations, Requirements, and Architectures for Smart Buildings-Energy Optimization and Next-Generation Building Management Systems", IEEE Internet of Things Journal 4(1), 2017, pp. 269-283.

[23] Mukhopadhyay, S.C., and N.K. Suryadevara, "Internet of things: Challenges and opportunities", In Smart Sensors, Measurement and Instrumentation. Springer, Cham, 2014, 1-17.

[24] Neuhofer, B., D. Buhalis, and A. Ladkin, "Smart technologies for personalized experiences: a case study in the hospitality domain", Electronic Markets 25(3), 2015, pp. 243-254.

[25] Oliveira, T., \& Martins, M.F., "Literature review of information technology adoption models at firm level", The Electronic Journal Information Systems Evaluation (EJISE) 14(1), 2011, pp. 110-121.

[26] Oliveira, T., and M.F. Martins, "Literature Review of Information Technology Adoption Models at Firm Level", The Electronic Journal Information Systems Evaluation 14(1), 2011, pp. 110-121.

[27] Racherla, P., and C. Hu, "eCRM system adoption by hospitality organizations: A technology-organizationenvironment (toe) framework", Journal of Hospitality and Leisure Marketing 17(1-2), 2008, pp. 30-58.

[28] Ramilo, R., and M.R. Bin Embi, "Critical analysis of key determinants and barriers to digital innovation adoption among architectural organizations", Frontiers of Architectural Research 3(4), 2014, pp. 431-451.

[29] Ruzzene, A., "The Case Study as Research Method: A Practical Handbook", International Studies in the Philosophy of Science 25(3), 2011, pp. 293-296.

[30] Spencer, B.F., M.E. Ruiz-Sandoval, and N. Kurata, "Smart sensing technology: Opportunities and challenges", Structural Control and Health Monitoring 11(4), 2004, pp. 349-368.

[31] Thong, J.Y.L.L., "An integrated model of information systems adoption in small businesses", Journal of management information systems 15(4), 1999, pp. 187214.

[32] Tornatzky, L.G., and M. Fleischer, "Processes of Technological Innovation (Issues in Organization and Management Series) Global innovation insight", 1990, pp. 298.

[33] Verdanix, Siemens And IBM Collaborate To Enhance Smart Buildings With IoT, 2016.

[34] Vermesan, O., and P. Friess, Internet of Things: Converging Technologies for Smart Environments and Integrated Ecosystems, River Publishers, 2013.

[35] Wang, S.K., and H.Y. Hsu, "Using the ADDIE model to design second life activities for online learners", TechTrends 53(6), 2009, pp. 76-81.

[36] Zhou, B., W. Li, K.W. Chan, et al., "Smart home energy management systems: Concept, configurations, and scheduling strategies", Renewable and Sustainable Energy Reviews 61(1), 2016, pp. 30-40. 